\title{
FUNGSI TARI BABANGSAI DALAM UPACARA ARUH GANAL DI DESA LOKSADO HULU SUNGAI SELATAN KALIMANTAN SELATAN
}

\author{
Oleh : Rahmani dan I Wayan Dana
}

\begin{abstract}
RINGKASAN
Tari Babangsai disajikan sebagai ungkapan rasa syukur dan rasa gembira atas berhasilnya panen padi. Tarian ini tersaji menjadi bagian tak terpisahkan dari pelaksanaan upcara Aruh Ganal. Kegembiraan masyarakat penyangga ini tampak terlihat dengan hadirnya masyarakat Loksado sebagai pelaku maupun penyelenggara upacara Aruh Ganal.

Penyelengaraan upacara Aruh Ganal diadalan setahun sekali, sesuai dengan ketentuan masyarakat adat Loksado Hulu Sungai di Kalimantan Selatan. Kehadiran tari Babangsari dalam upacara Aruh Ganal berfungsi sebagai sarana upcara di satu sisi, dan di sisi yang lain juga untuk hiburan bagi masyarakat pelaku upacara sehingga dapat melaksanakan upacara secara berurutan selama tujuh hari tujuh malam.
\end{abstract}

Kata Kunci: Babangsai, upacara Aruh Ganal, dan fungsi.

\section{ABSTRACT}

The Babangsaidance is performed as an expression of thankfulness and happiness due to the successful rice harvest. This dance is an inseparable part of the AruhGanalceremony. The joyfulness of the supporting community can be seen from the presence of the members of Loksado society as both the performers and organizers of the ceremony.

The AruhGanalceremony is carried out once a year, that is in accordance with the rule of the society of the village of river upstream Loksado, south Borneo. The existence of the Babangsaidance in the AruhGanalritual ceremony functions as a means of ceremony on one hand, and as an entertainment for the society carrying out the ritual ceremony on the other. Consequently, the ceremony may take place continually for seven days and seven nights.

Key words: Babangsai, AruhGanal, ceremony and function

\section{A. PENDAHULUAN}

Salah satu unsur kebudayaan adalah kesenian, yangmemiliki dayajuang dan daya tahan apabila memiliki fungsi atau peranan dalam kehidupan masyarakatnya. Sebuah bentuk seni pertunjukan akan tetap bertahan dan berkembang dalam kehidupan masyarakat pendukungnya selama masih dibutuhkan dan mempunyai fungsi sosial-kultural dalam kehidupan masyarakat (Haryono, 2008: 11). Dari berbagai kesenian yang hidup dan berkembang di nusantara adalahtari Babangsai, memiliki fungsi bagi kehidupan sosial-budaya masyarakat Dayak Loksado yang menjadi bagian tidak terpisahkan dari pelaksanaan upacara religi mereka. 
Masyarakat Dayak Loksado hingga dewasa ini masih menjalankan upacaraupacara secara turun temurun, yaitu upacara AruhGanal(kenduri besar atau panen raya). PelaksanaanAruhGanal sebagai upacara ritual dijalankan oleh masyarakat penyangganya berdasarkan aturan dan tindakan khusus. Berpijak dari paparan Ronald L. Grimes, di ketengahkan bahwa ritual sebagai suatu perpaduan dari beberapa jenis tindakan mencakup bernyanyi, bermain drama, dan menari, serta menjelaskan ritus atau ritual sebagai suatu tipe perilaku yang menunjukkan suatu aturan dalam ruang dan waktu khusus. Ritus merupakan serangkaian dari beberapa tindakan yang secara luas dikenal oleh anggotanya tentang relasi diri sendiri dengan dunia dan Yang Ilahi (dalam Kreinath, Snoek, \& Michael Stauberg, 2006: 379).Berpijak dari pendapat itu, makaAruh Ganal sebagai upacara ritual, terlihat dengan jelas adanya pemujaan terhadap arwah nenek moyang atas tuntunan kesejahteraan yang dilimpahkan pada turunnannya, melalui hasil panen yang melimpah. Para roh pemelihara hutan dan alam raya dipanggil dalam pelaksanaan upacara tersebut.Oleh karena itu, dalam upacara AruhGanal baik tindakan, pelaku, dan sarana pendukung sangat diperhatikan sesuai dengan tata cara dan aturan yang ditentukan dalam pelaksanaan upacara ritual masyarakat Dayak Loksado.

Pelaksanaan upacara AruhGanal selalu menghadirkan seni pertunjukan salah satunya adalah tari Babangsai.Tari ini merupakan sarana atau kelengkapan sebuah upacara, sehingga sajian tari ini menjadi satu kesatuan dalam upacara AruhGanal.Tari Babangsai dalam upacara AruhGanal jelas berada dalam deretan fungsi yang sangat penting tersussun dengan upacara. Sejalan dengan itu, Radcliffe Brown (1980: 208) menyatakan bahwa suatu fungsi merupakan sumbangan dimana aktivitas sesuatu bagian melakukan aktivitas secara keseluruhan. Demikian halnya dengan tari Babangsai yang merupakan satu kesatuan yang saling berhubungan dalam upacara Aruh Ganal dan mempunyai pengaruh penting di lingkungan sosial-budaya masyarakat Dayak Loksado. Dalam hal ini, tampak terlihat jelas bahwa hubungan upacara AruhGanal dan tari Babangsai, terjadi saling keterkaitan dan saling memberi kekuatan fungsi satu sama lainnya

Tari Babangsai hadir dalam bentuk seni pertunjukan ritual dan merupakan salah satu kekayaan lokal yang memiliki fungsi sakral bagi masyarakat pendukungnya. Mengingat bahwa fungsi seni pertunjukan dapat diklasifikasikan menjadi dua, yaitu fungsi primer dan fungsi sekunder (R.M. Soedarsono, 2002: 126).Fungsi primer seni pertunjukan mencakup sebagai sarana ritual, hiburan pribadi, dan presentasi estetis. Fungsi sekunder menunjukkan semangat dalam kebersamaan dan sebagai media komunikasi antara dan di antara para penyangga upacara AruhGanal. Berangkat dari paparan latar belakang, maka muncul beberapa masalah yang perlu dikaji lebih lanjut agar mendapat jawaban secara komprehensif. Dengan demikian, permasalahan dapat dirumuskan dalam dua bentuk pertanyaan utama dan menarik diungkap sebagai berikut. (1)Apa fungsi tari Babangsai dalam upacara Aruh Ganal; dan (2)Mengapa tari Babangsaisenantiasa hadir dalam setiap pelaksanaan upacara Aruh Ganal di Desa Loksado? Pertanyan-pertanyaan itu sebagai pokok permasalahan atau fokus kajian yang diharapkan bisa memberi arah bagi pengungkapan sosial-budaya masyarakat pelaksana upacara Aruh Ganal di Desa Loksado Hulu Sungai Selatan, Kalimantan Selatan.

\section{B. Fungsi Tari Babangsai}

Tari Babangsai dalam kehidupan masyarakat Dayak Loksado menyandang fungsi sebagai sarana ritual. Dikatakan demikian, karena tarian tersebut menjadi bagian tak terpisahkan dari keseluruhan rangkaian upacara AruhGanal. Demikian, halnya dipertegas oleh (R.M. Soedarsono 2002: 126) bahwa fungsi seni sebagai ritual, diperlukan tempat pertunjukan yang terpilih, 
pemilihan hari serta waktu yang juga dianggap sakral, diperlukan pemain atau penari yang terpilih. Di samping itu, pelaksanaannya didukung seperangakat sesajidan tujuan lebih penting dari pada nilai estetis, serta diperlukan rias-busana yang khasatau khusus untuk ritual.

\section{Tempat Pertunjukan}

Upacara AruhGanal dilaksanakan pada sebuah bangunan yang disebut Balai adat.Balai adat adalah tempat tinggal beberapa umbun (keluarga). Ukuran Balai memiliki lebar mencapai 15 (lima belas) sampai 20 (dua puluh) meter dan panjang sekitar 50 (lima puluh) meter. Bangunan itu, dibangun oleh umbun diatas tiang yang tingginya kurang lebih 3 (tiga) meter dari permukaan tanah. Dibagian depan halaman Balai terdapat ruang terbuka untuk menjemur padi hasil panen raya Dayak Loksado.
Balai adat terdiri dari tiga ruang utama yaitu, ruang kamar untuk para umbun (keluarga) tidur, ruang bersama berada didepan kamar yang berfungsi sebagai tempat para umbun duduk-duduk bersosialisi menerima tamu, dan ruang pematang (ruang upacara) yang berada ditengah-tengah Balai adat. Ruang pematang ini memiliki fungsi utama sebagai tempat dilaksanakannya upacara-upacara adat khususnya upacara AruhGanal.

Di tengah-tengah ruang pematangBalai adat mempunyai tempat kedudukkannya tersendiri.Di ruang pematang didirikan sebuah Lalaya (altar persembahan) yang terbuat dari buluh kuning (bambu kuning), dirancang sedemikian rupa berbentuk panggung dihias denganjanur kelapa muda dan ringgitan, seperti terlihat pada gambar di bawah ini.

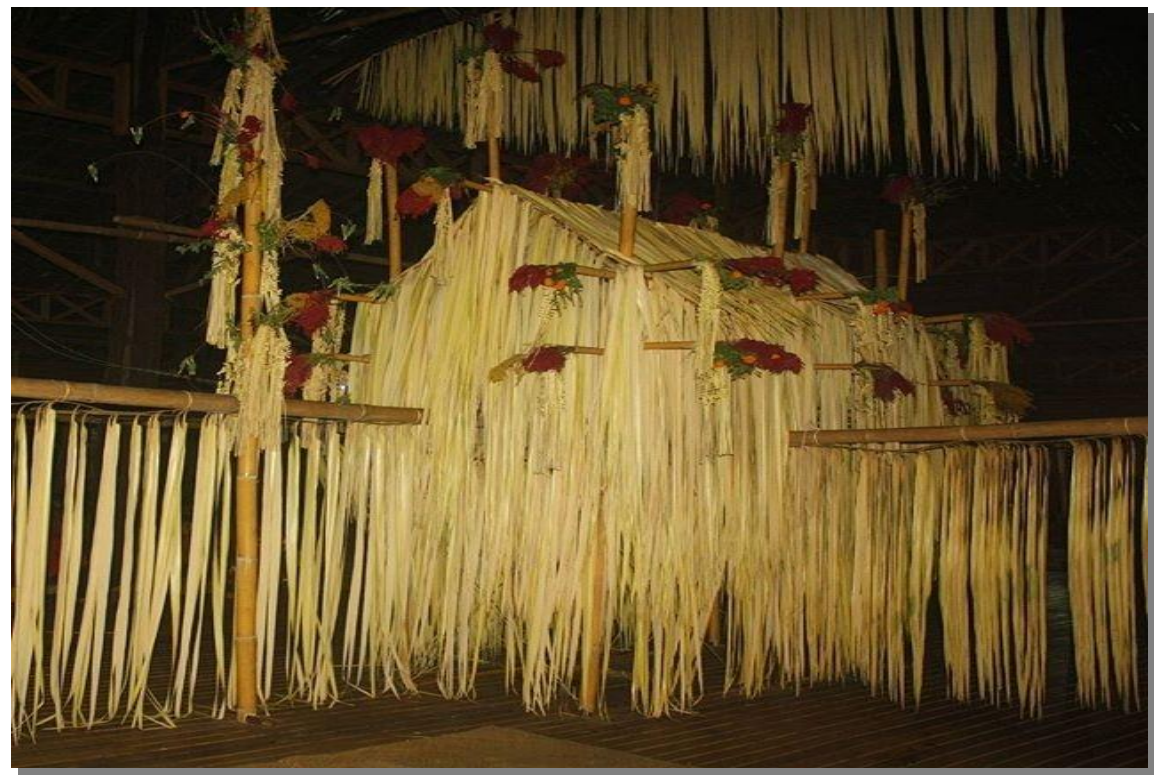

Gambar 1.Lalaya yang berada di tengah ruang Balaiadat

(Dokumentasi Rahmani, 2015)

Lalaya ini berfungsi sebagai tempat masyarakat meletakkan bermacam sesajen, hasil panen, dan sejumlah penganan khusus upacara AruhGanal.Lalaya dilambangakan sebagai tempat berkumpulnya para dewata, roh-roh gaib, dan para penguasa bumi, sehingga menjadi tempat yang sangat disakralkan oleh masyarakat penyangganya.
Menurut Ayal Kusal, Lalaya merupakan tempat berkumpulnya para roh nenek moyang yang hadir diundang pada saat upacara (wawancara, 10 April 2016). Dengan demikian, seluruh rangkaian upacara AruhGanal termasuk penyajian tari Babangsai berpusat pada Lalaya sebagai titik paling sakral di dalam Balai adat. 


\section{Waktu Pelaksanaan}

Upacara Aruh Ganal rutin diadakan setiap tahun sekali oleh masyarakat Dayak Loksado. Upacara ini dilaksanakan setelah panen raya yang jatuh pada dikisaran bulan Juni atau Juli. Untuk menetapkan waktu pelaksanaannya, masyarakat melakukan musyawarah desa yang dipimpin oleh Damang (Kepala Adat). Ada hari-hari tertentu dipandang tepat sesuai perhitungan metologis masyarakat Dayak Loksado.Keyakinan itu berkenaan dengan hari penciptaan manusia, padi, mahluk hidup, dan benda-benda yang ada di bumi. Menurut Ayal Kusal, manusia diciptakan pada hari pertama. Kemudian, di hari kedua diciptakan wasi (besi), pada hari ketiga diciptakan banih (padi), pada hari keempat diciptakan amas (emas) dan perak, pada hari kelima diciptakan pakaian manusia, serta pada hari keenam diciptakan hewanhewan (wawancara, 20 Maret 2016).

Berdasarkan pandangan itu, masyarakat Dayak Loksado beranggapan bahwa hari pertama, kedua, dan ketiga dianggap baik dalam melaksanakan upacara AruhGanal. Perhitungan hari itu, berdasarkan hidupbulan fenomena munculnya bulan diatas langit.Bila bulan dilangit hidup (berusia) satu hari, maka hari itu diidentifikasikan sebagai hari pertama dan demikian seterusnya. Oleh sebab itu, salah satu dari hidup bulan mulai dari 1(satu) sampai 15(lima belas) hari umumnya dilaksanakan upacara AruhGanal. Mereka, masyarakat Dayak Loksado menyakini apabila upacara dilaksanakan pada tanggal itu,akan diperoleh rezeki dan kesejahteraan hidup bagi masyarakat.

Aruh Ganal selalu dimulai pada malam hari dan berakhir pada besok paginya. Upacara ini dilaksanakan selama 7 (tujuh) hari berturutturut. Pemilihan malam hari sebagai pelaksanaan upacara adalah berkaitan dengan kepercayaan masyarakat Dayak Loksado penganut agama Kaharingan, bahwa malam hari itu adalah waktu dimana para roh gaib mudah untuk dipanggil dan dipuja.

Penyajian tari Babangsai sebagai bagian upacara memiliki keterkaitan dengan perhitungan hari dan waktu untuk menentukan pelaksanaan upacara AruhGanal. Di setiap pelaksanaan upacara AruhGanal, tari Babangsai disajikan diawal upacara, sehingga tarian ini menjadi tanda awal upacara, sebelum menuju ketahapan berikutnya. Sajian tari Babangsai sebagai bagian dan menandakan pelaksanaan upacara dimulai dapat dilihat pada gambar di bawah ini.

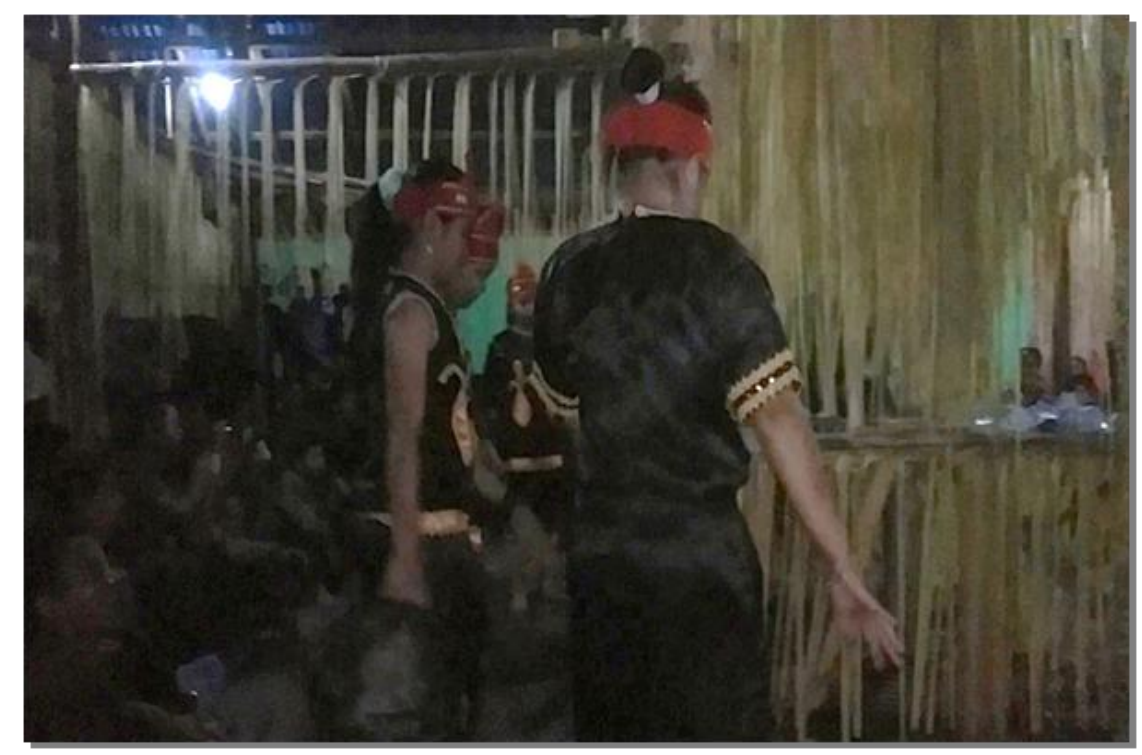

Gambar 2. Penyajian tari Babangsai di awal upacara AruhGanal (Dokumentasi Rahmani, 2015) 
JOGED

ISSN: $1858-3989$
Rahmani dan I Wayan Dana (FUNGSI TARI BABANGSAI DALAM UPACARA ARUH GANAL DI DESA LOKSADO HULU SUNGAI SELATAN KALIMANTAN SELATAN)
Penyajian tari Babangsai diawal
upacara penyambutan para roh DatuNini (nenek moyang). Selain itu, Babangsai juga sebagai simbol ungkapan suka ria masyarakat Lokssado terhadap roh nenek moyang yang berkenan hadir di tengah-tengah pelaksanaan upacara AruhGanal. Penyajian tari Babangsai biasanya dimulai sekitar pukul 9 (sembilan) malam setelah Balian membakar kemenyan dan membacakan mamang (mantra). Pemilihan waktu di malam hari, menjadi ketentuan adat Dayak Loksado dalam melaksanakan upacara AruhGanal. Masyarakat percaya bahwa pada saat tengah malam hari roh-roh gaib mudah dipanggil untuk menghadiri pelaksanaan upacara. Dengan demilihan, penentuan waktu ini membuktikan bahwa, penyajian tari Babangsai sangat diperhitungkan dalam keberhasilan pelaksanaannya karena sesuai dengan pijakan tata cara upacaramasyarakat Dayak Loksado.

\section{Pelaku}

Semua penari atau pelaku tari Babangsai terdiri dari kaum perempuan. Perempuan bagi masyarakat Dayak Loksado dianggap sebagai indung atau ibu dari seluruh yang diciptakan Sang Kuasa. Oleh karena itu, semua penari Babangsai adalah perempuan, mulai dari anak-anak, remaja sampai dengan orang tua. Menurut Ayal Setiap perempuan yang menarikan tari Babangsai dalam upacara AruhGanal harus bersih dan suci lahir batin. Bahkan, seluruh pelaku dalam upacara AruhGanal harus dalam keadaan bersih dan suci (wawancara, 10 April 2016). Bersih dan suci dalam hal ini, dimaksudkan bahwa bagi para perempuan tidak dalam keadaan haid. Apabila terjadi seseorang penari dalam keadaan haid, baik sebelum atau saat menarikan Babangsai maka ia harus digantikan oleh penari yang lain. Jika larangan ini tidak dilaksanakan, maka saat memanggil roh-roh nenek moyang tidak akan hadir dalam upacara Aruh Ganal. Oleh sebeb itu, sebelum menari Babangsai para Balian (pimpinan upacara) terlebih dahulu membakar kemenyan dan bamamang (membaca mantra). Bamamang dipergunakan sebagai cara untuk memberitahukan bahwa penyajian tari Babangsai segera dilaksanakan dan juga cara seorang Balian membersihkan diri para penari secara spiritual. Bamamang juga diungkap sebagai cara seorang Balian berkomunikasi dengan roh-roh nenek moyang untuk mengukuhkan sajian tari Babangsai sebagai bagian tak terpisahkan dengan Aruh Ganal.

Balian sebagai pemimpin upacara dikelompokkan menjadi 3 (tiga) tingkatan yaitu BalianAnum (muda) mereka yang baru belajar terutama menghafal dan memahami sejumlah mamang. BalianTangah (tengah), bagi mereka yang sudah bisa menggantikan sementara pimpinan upacara. BalianTuha (tua), yaitu orang yang berwenang penuh memimpin upacara-upacara religi maupun adat dalam masyarakat Loksado.

Untuk menjadi seorang BalianTuha, ditentukan oleh faktor usia dan pengalaman hidup, serta mampu menguasai semua proses suatu upacara religi. Di samping itu, sudah tentu yang bersangkutan memiliki kemampuan memimpin upacara AruhGanal dari awal hingga akhir pelaksanaan. Dengan demikian, ia juga memiliki ketahanan pisik maupun non pisik mampu tidak tidur selama beberapa hari secara berturut-turut selama berlangsungnya upacara. BalianTuha adalah orang yang sangat disegani dihormati di lingkungan masyarakatnya. BalianTuha biasanya memiliki kesempatan untuk berpergian jauh keluar kampung untuk menghadiri atau memimpin suatu upacara keagamaan. Sering juga diminta oleh masyarakat tertentu diminta datang untuk melakukan pengobatan tradisional bagi orang yang terkena penyakit tertentu. Seorang BalianTuha biasanya memiliki ingunan (kekuatan gaib) tertentu yang membantunya dalam aktivitas pengobatan maupun berkomunikasi dengan roh-roh gaib lainnya.

Dalam melaksanakan upacara Balian didampingi oleh seorang Patati. Patati adalah orang yang menjawab pertanyaan-pertanyaan Balian di saat mengalami trance (kerasukan) kekuatan gaib. Patati juga menjelaskan kepada 
Balian tentang permintaan dan keinginan para peserta aruh. Pada dasarrnya menjadi seorang Patati harus memenuhi persayaratan tertentu. Syaratnya harus mengetahui semua cara berkomunikasi dengan roh-roh gaib dan terampil menabuh gandang (gendang) secara tepat dan benar. Seorang Patati, disamping memenuhi persyaratan seperti itu, pemilihannya juga didasari atas pertimbangan usia. Menjadi seorang Patati disepakati usia tua, baik secara lahiriah maupun memiliki wawasan dan pengalaman serta pengetahuan luas tentang agama atau kepercayaan dan adatistiadat.

Pelaku upacara lainya adalah termasuk penabuh gandang (gandang). Penabuh gendang dalam upacara AruhGanal pada umumnya adalah wanita. Wanita atau perempuan bagi masyarakat Dayak Loksado mengambil jalanbini-bini (jalur komunikasi dengan roh-roh perempuan). Oleh karena itu, wanita dianggap lebih berperan penting dalam aktivitas setiap rangkaian upacara aruh.

\section{Sesajen}

Dalam upacara AruhGanal memiliki bermacam-macam bentuk sesaji yang dipersembahkan untuk NangKuasa (Hyang Kuasa), para roh-roh nenek moyang, dan tokoh-tokoh gaib lainya. Setiap sesajen yang dipersembahkan bukan sekedar kelengkapan upacara, namun terkandung makna yang dalam sehingga harus dihadirkan. Bentuk sesaji dalam upacara AruhGanal di antaranya adalah lamang, sebagai lambang ungkapan rasa syukur terhadap Sang Pencipta;wadailambuk melambangkan kegotong-royongan dalam masyarakat Loksado; ringgitan sebagai lambang kesucian diri manusia;gilingpinang, lambang penghormatan kepada roh-roh nenek moyang; anaknasi sebagai lambang hadirnya satu kesatuan keluarga yang utuh.Apaun macam sesaji itu dapat dilihat pada gambar di bawah ini.

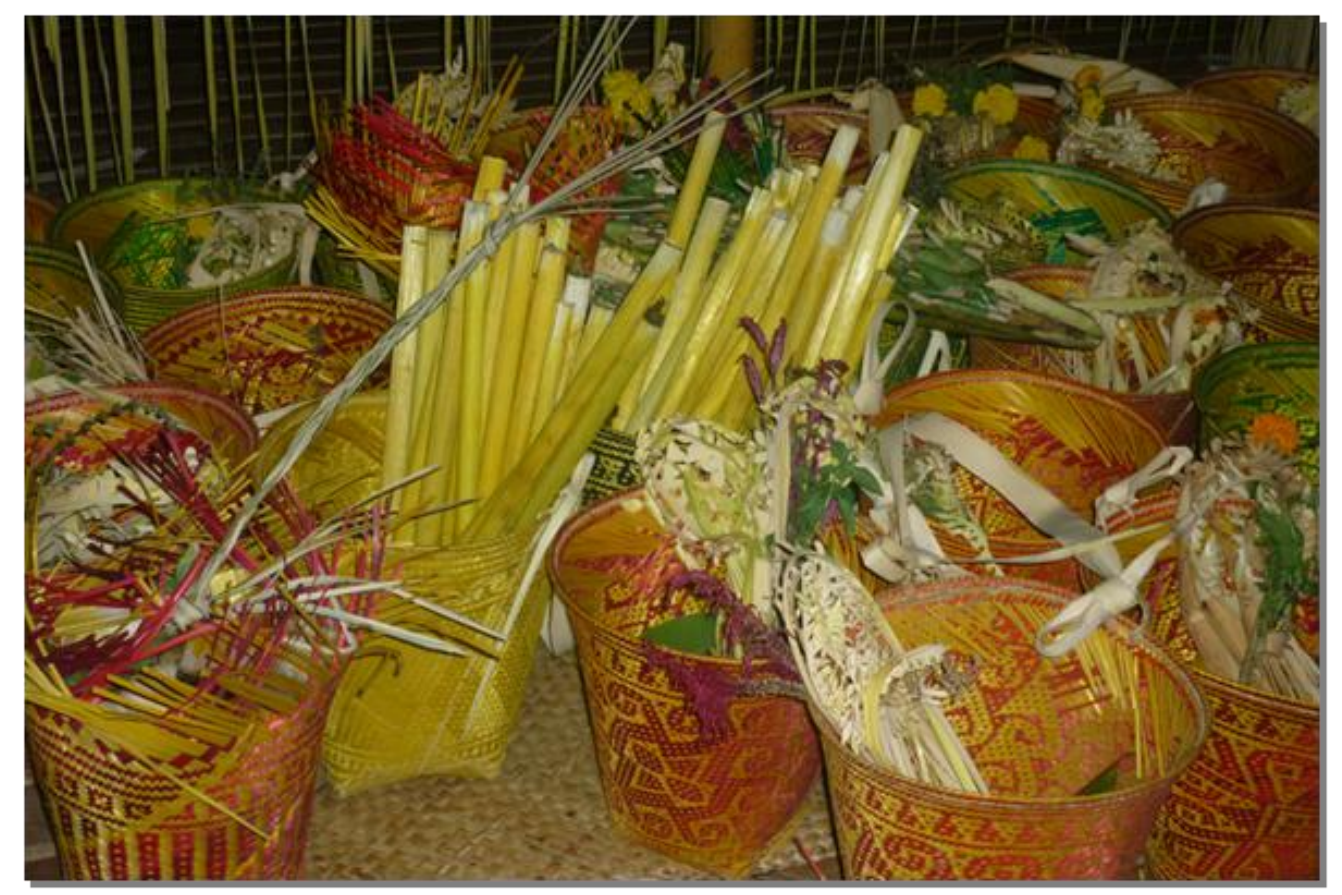

Gambar 3. Macam Sesaji upacara AruhGanal

(Dokumentasi Rahmani, 2015) 
JOGED

ISSN: $1858-3989$
Rahmani dan I Wayan Dana (FUNGSI TARI BABANGSAI DALAM UPACARA ARUH GANAL DI DESA LOKSADO HULU SUNGAI SELATAN KALIMANTAN SELATAN)
Pada dasarnya persembahan semua sasaji itu dimaksudkan sebagai tanda terima kasih masyarakat penyangga upacara kepada NangKuasa-kuasa, agar mengabulkan segala permohonan kesejahteraan dan menjauhkan segala bentuk bencana. Tanpa hadirnya sesaji, maka pelaksanaan upacara AruhGanal mustahil akan dilaksanakan. Jadi, jelas bahwa keberadaan sesaji di dalam pelaksanaan upacara AruhGanal merupakan bagian yang tidak bisa terpisahkan.

Menurut Damang Ayal dalam melaksanakan upacara tidak mempersoalkan kostum apa yang dipakai, yang penting dilandasi kesungguhan melaksanakan upacara dengan hati yang bersih. Tuhan atau Yang Kuasa tidak memandang umatnya melalui pakaian yang dikenakan (wawancara, 10 April 2016). Dalam hal ini, pakaian dianggap bukan satu-satunya menjadi ketentuan dalam melaksanakan upacara.Walaupun demikian, bukan berarti Balian bebas mengenakan pakain pada saat memimpin upacara. Ia tetap memakai beberapa kelengkapan yang harus dikenakan sebagai tanda pimpinan upacara. Kelengkapan pakiannya terdiri dari laung (ikat kepala) ; balacu (sabuk); dan tapihtanjung (sarung). Laung terbuat dari sehelai kain persegi empat dengan ukuran kurang lebih 40 $\mathrm{cm}$, warna dasarnya putih, dan bagian tepinya dihiasi motif bunga.Para Balian menyebutnya kain bawatun. Kain bawatun awalnya dilipatlipat sampai membentuk segitiga samakaki. Kemudian bagian bawah kain dilipat lagi sebanyak 2 atau 3 kali lipatan berukuran lebar 2 jari atau kurang lebih 2 sampai $3 \mathrm{~cm}$. Selanjutnya padabagian bawah yang dilipat, dibelitkan di kepala mulai dari depan sampai belakang kepala dan akhirnya diikat kuat ujungnya. Ikatan dibuat secara khusus dinamakan menandukkijangjurungan (seperti tanduk kijang), karena kedua ujung simpul menjulang ke atas seperti tanduk kijang.

Selain memakai laung, para Balian juga mengenakan tapihtanjung bermotif kotakkotak berwarna dasar merah atau biru tua.Cara pemakaian tapihtanjung dilipat memanjang kemudian dililitkan di pinggang setinggi lutut.
Untuk menguatkan lilitan tapihtanjung, maka diikat dengan kain belacuputih yang ukurannya lebih pendek dari tapih tanjung.

Hadirnya tari Babangsai dalam upacara AruhGanal sebagai bentuk ungkapan rasa syukur terhadap hasil panen yang melimpah dan juga sebagai penyambutan roh-roh gaib yang hadir menyaksikan upacara. Oleh karena itu, penyajian tari Babangsai tampak tidak mengutamakan penampilan secara estetik, akan tetapi menjadi proses berjalannya upacara AruhGanal dengan sempurna. Dengan demikian,tari Babangsai sangat disakralkan oleh masyarakat setempat. Kesakralannya didukung dengan penggunaan baju tanganhandap (lengan pendek) motif kababitak (motif laba-laba), laung (ikat kepala), dan salawarhandapbukit (celana bukit). Baju tanganhandap dari kain berwarna hitam dengan manik-manik warna emas bermotif kababitak didepan dada, lengannya dihiasi jalinan rumbai (juntaian kain) bewarna kuning. Salawarhandapbukit dari kain bewarna hitam dengan ukuran satangahtihang (antar lutut dan mata kaki). Laung terbuat dari kain berwana hitam berbentuk persegi panjang. Ukuran panjang kurang lebih $40 \mathrm{~cm}$, dihias dengan manik-manik di sekeliling sisinya.

Tari Babangsai, selain sebagai sarana ritual, tari ini juga memiliki fungsi sebagai sarana hiburan dan pengikat solidaritas masyarakat. Manakala tari disajikan sebagai sarana hiburan, maka tarian ini dapat memberikan ruang bagi para pelaku upacara atau pihak yang terlibat untuk bersuka ria, saling menghibur diri, baik dengan menari bersama, ataupun hanya dengan menyaksikan saja. Hadirnya suasana suka-cita seperti ini dapat menghibur setiap orang sebagai bagian pelepas dari ketegangan-ketegangan dalam aktivitas sehari-hari, termasuk dalam pelaksanaan upacara AruhGanal.

Fungsi tari sebagai hiburan tidak hanya terjadi pada peristiwa yang khusus diadakan untuk hiburan.Artinyasuatu pertunjukan sebagai hiburan, bukan berarti sama sekali tidak mengandung nilai-nilai spiritual. Dari 
hasil pengamatan di lapangan di berbagai daerah, seperti Topeng Sidahakarya, Barong, dan pertunjukan tari Babangsai, memperlihatkan bahwa selain berfungsi sebagai tari ritual dalam upacara AruhGanal, di sisi lain juga berfungsi sebagai sarana hiburan bagi sebagian masyarakat yang hadir dalam upacara. Masyarakat yang hadir sebagai penyangga upacara, maka dalam waktu bersamaan juga mengundang masyarakat dari desa-desa lain termasuk para pejabat pemerintahan. Masyarakat dan undangan yang hadir dalam upacara itu meliputi anak-anak hingga orang tua, baik laki-laki maupun perempuan, turut berbaur ikut menyaksikan kemeriahkan upacara Aruh Ganal. Kehadiran mereka ke tempat upacara pada umumnya selain mengikuti jalannya upacara, ternyata berorientasi untuk memperoleh hiburan.Hal ini, tercermin dalam sikap para undangan yang hadir sebagainnya bukan penganut agama Kaharingan. Mereka lebih tertarik menyaksikan tari Babangsai yang hadir dalam pelaksanaan upacara AruhGanal terutama pada perayaan malam kedua.Sajian tari Babangsai di malam kedua dipertunjukan secara 'bebas' dan tidak memakai kostum tari seperti kehadiran Babangsai malam hari pertama. Adapun bagian tari Babangsai malam hari kedua tampak pada gambar di bawah ini.

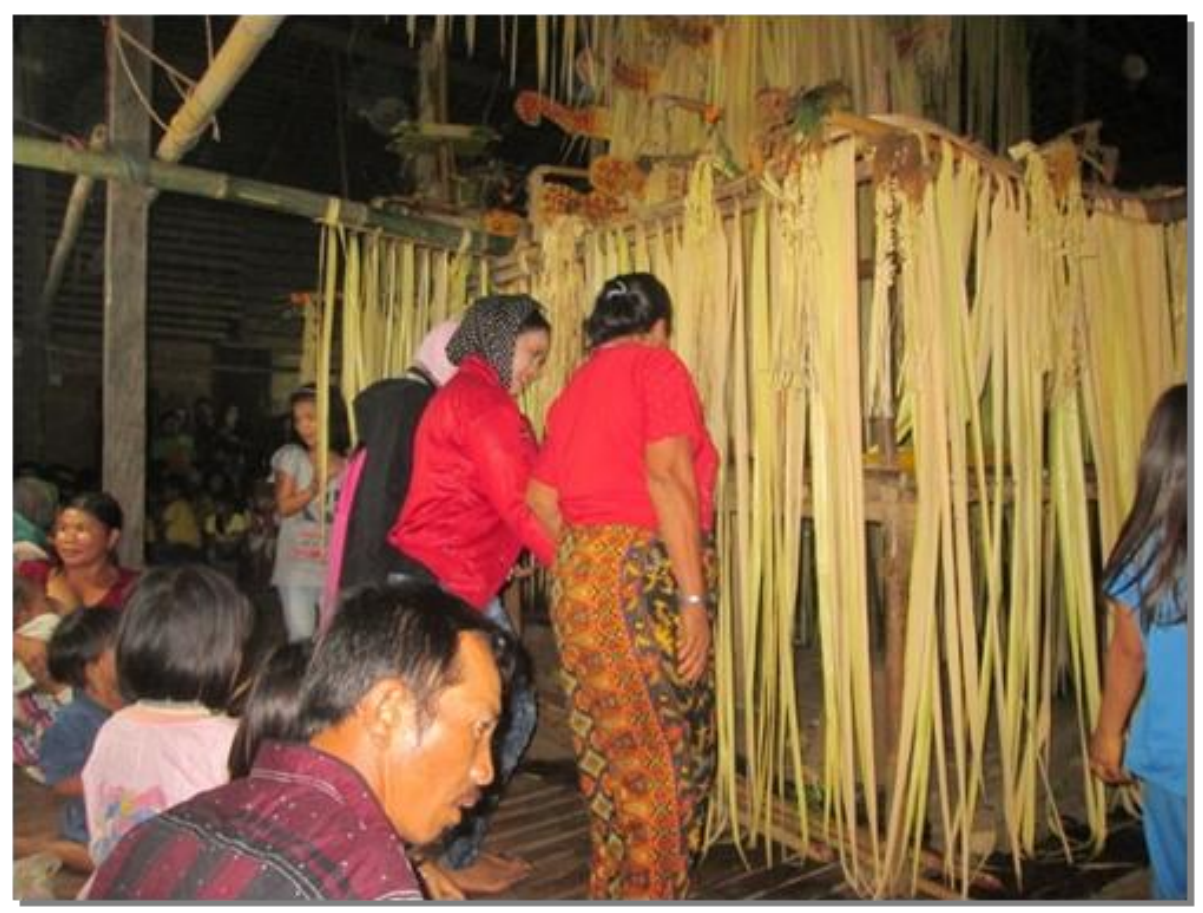

Gambar 4.Tampak sebagaian tamu undangan, anak-anak, dan masyarakatsetempat menarikan tari Babangsai untuk menghibur diri.

(Dokumentasi Rahmani, 2015)

Karya seni pada umumnya diciptakan oleh para penciptanya, termasuk tari Babangsaitentu melalui proses internalisasi dalam masyarakat penyangganya sehingga menguatkan antara teks dan konteksnya. Oleh karena itu kesenian mampu hidup dan berkembangsesuai dengan fungsi serta jiwa jaman setempat.Seni senantiasa hidup selaras dengan tata nilai yang terbagun dimasyarakat, ia (perujudan seni itu) berfungsi sebagai 
dinamisasi kehidupan masyarakat dari yang ritual hingga hiburan atau melepas ketegangan jiwa, menghibur diri kebebasan berekspresi sesuai media ungkapnya. Demikian halnya tari Babangsai yang hidup dan berkembang di lingkungan masyarakat Loksado Hulu Sungai Selatan, Kalimantan Selatan. Tarian ini di satu sisi difungsikan sebagai sarana ritual dalam upacara Aruh Ganal dan di sisi lain juga berfungsi untuk membangun solidaritas masyarakat sehingga mampu menjadi perekat antar warga, bahkan difungsikan sebagai hiburan bagi peserta upacara. Walaupun demikian, masyarakat Loksado tetap berpegang pada fungsi utama kesenian tersebut yaknisebagai sarana ritual upacara AruhGanal di malam hari pertama, dan di malam hari berikutnya sebagai pertunjukan hiburan.

\section{Penutup}

AruhGanal juga menjadi ajang paling efektif untuk menumbuhkan rasa solidaritas, membangun kebersamaan, dan saling mengenal satu sama lainya. Hal itu tecermin dari aktivitas mereka sejak mempersiapkan peralatan hingga pelaksanaan upacara.Dengan senang hati dan penuh kesadaran masyarakat Dayak Loksado mempersiapkan berbagai perlengkapan yang dibutuhkan agar upacara dapat berlangsung dengan baik dan lancar. Tanpa terjalinnya kerja sama dan rasa kegotong-royongan yang baik, maka sajian tari Babangsai dalam upacara AruhGanal mustahil dapat diselenggarakan. Pada saat pelaksanaan upacara Aruh Ganal, semua lapisan masyarakat Loksado ikut membaur untuk menyaksikan jalannya upacara. Masyarakat yang datang ke Balai tempat pelaksanaan upacara tidak saja bagipenganut kepercayaan Kaharingan.Semua penganut agama bersatu padu untuk menikmati peristiwa budaya yang disajikan lewat upacara adat Aruh Ganal. Sikap saling menghormati antar umat beragama diwujudkan dengan mengikuti jalannya upacara sejak mulai hari pertama hingga tujuh hari berikutnya dengan tertib dan mematuhi segala peraturan adat setempat dalam suasana sukacita.

Upacara Aruh Ganal merupakan ungkapan rasa syukur masyarakat Loksado atashasil panen yang melimpah. AruhGanal juga sebagai cara beribadat masyarakat Dayak Loksado yang memiliki kedudukan sangat sakral.Melalui tari Babangsai digunakan sebagai tata cara untuk memuja dan menghormati segala yang mereka sakralkan pada saat upacara. Tarian ini selalu terangkai dengan upacara AruhGanal dan menjadi bagian yang tidak bisa dipisahkan. Babangsai dalam upacara AruhGanal, melambangkan ungkapan rasa syukur dan penghormatan kepada para roh nenek moyang dan penguasa alam lainnya. Hal mengukuhkan fungsi tari Babangsai berkaitan erat dengan kehidupan masyarakat mpenganut kepercayaan Kaharingan di Desa Loksado. Tari menjadi bagian yang tak terpisahkan dari kehidupan sehingga mereka senantiasa menjaga nilai-nilai ketradisian yang terkandung dalam balutan nilai-nilai keagamaan. Selain tari Babangsai sebagai sarana ritual, tari ini juga memiliki nilai moral yang sangat tinggi yaitu kekeluargaan, solidaritas, dan memupuk rasa kesatuan maupun persatuan. Hal ini didorong karena masyarakat Dayak Loksado mengungkapkan syukur dan bersuka ria lewat ungkapan tarian, dan tetap berpegang teguh pada kepercayaan Kaharingan. Oleh karena itu, tari Babangsai bukan hanya produk profan yang menyatakan kekuatanya dalam dimensi hiburan belaka, tetapi lebih kepada penyatuan manusia dengan Tuhan dan alam sekitarnya yang memberi hidup dan kehidupan.

\section{DAFTAR PUSTAKA}

Ahmad Syadzali\& Tahniyatus. (2013), Dealiktika Budaya Banjar,Tahura Media, Banjarmasin.

Daut, Alfani. (1997),Islam dan Masyarakat Banjar, P.T. Raja Grafindo Persada, Jakarta. 
Dhavamony, Mariasusai. (1995), Fenomenologi Agama, Kanisius, Yogyakarta.

Eliade, Mircea. (1959), The sacred and the profane atau Sakral dan Profan,terjemahan Nuwanto.(2002), Fajar Pustaka Baru, Yogyakarta.

Endraswara, Suwardi. (2006), Metodologi Penelitian Kebudayaan, Gadjah Mada Press., Yogyakarta.

Hadi, Y.Sumandiyo. (2003), Aspek-aspek Dasar Koreografi Kelompok, ELKAPHI, Yogyakarta.

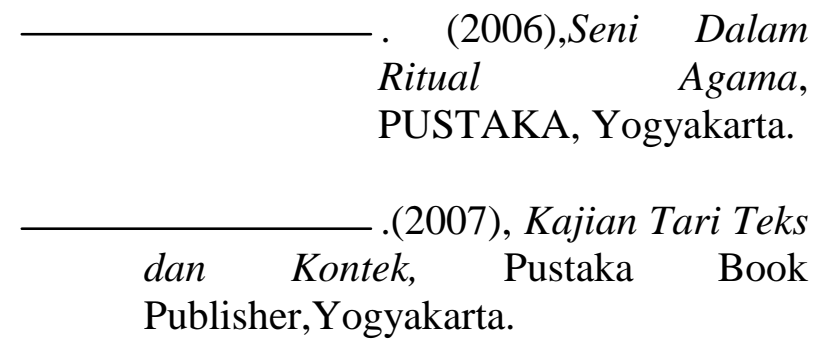
(2005), SosiologiTari, Pustaka, Yogyakarta.

(Bentuk-Teknik-Isi),
$\begin{aligned} & \text { Yogyakarta. } \\ & \text { Cipta Moreografi }\end{aligned}$

Haryono, Timbul. (2008), Seni Pertunjukan dan Seni Rupa dalam Perspektif Arkeologi, ISI Press., Surakarta.

Havilan, William A. (1988), Antropologi Jilid 2, Terjemah R.G. Soekadijo, Erlangga, Jakarta.

Hawkins, Alma M. (1988) Creating Through Danceatau Mencipta Lewat Tari, terjemahan Y. Sumandiyo Hadi. (1990), Institut Seni Indonesia Yogyakarta, Yogyakarta.

Ideham, M. Suriansyah, B.A, Syarifuddin, M. Zainal Arifin Anis \& Wajidi. (2007),
Urang Banjar Dan Kebudayaannya, Pustaka Banua, Banjarmasin.

Kusmayati, A.M. Hermien. (2000), ArakArakan Seni Pertunjukan dalam Upacara Tradisional di Madura, Yayasan Untuk Indonesia.Yogyakarta.

Kreinath, Snoek, dan Michale Stausber, (2006), Theorizing Rituals: Issues, Topics, Approaches, concepts, Brill, Leiden.

Maman, Muhlis. (2009), Sekilas Tentang Seni Tradisi Kalimantan Selatan, UPTD Taman Budaya Kalimantan Selatan, Banjarmasin.

Maunati, Yekti. (2004),Identitas Dayak Komodikasi dan Politik Kebudayaan, LKIS, Yogyakarta.

Muhrotien, Andreas. (2012),Rekontruksi Identitas Dayak, TICI Publication. Yogyakarta.

Proyek Pembinaan Perguruan Tinggi Agama IAIN Antasari Banjarmasin. (1978), Upacara Leligi dan Beberapa Adat Istiadat Masyarakat Pegunungan Meratus di Kalimantan Selatan, Institut Agama Islam Negeri Antasari, Banjarmasin.

Radam, Noerid Haloei. (2001),Religi Orang Bukit, Yayasan Semesta, Yogyakarta.

Radcliffe-Brown, A.R. (1950), Struktur dan FungsidalamMasyarakat Primitif, terj. A.Razak, Dewan Bahasa dan Kementrian Malaysia, Kuala Lumpur.

Salim, H. (1996), Islam Banjar, Relasi Antar Etnik dan Pembangunan, Interfidei, Yogyakarta.

(1996),Masyarakat Banjar, Relasi antar Etnik dan Pembangunan, dalam Hairus Salim (ed.). "Kisah dari Kampung Halaman; 
Masyarakat Suku, Agama Resmi, dan Pembangunan", Dian Interfidei,

Yogyakarta.

Susanto, P.S. Hary.(1987),Mitos Menurut Pemikiran Mircea Eliade, Kanisius, Yogyakarta.

Soedarsono, R.M. (2001),Metodologi Penelitian Seni Pertunjukan dan Seni Rupa, MSPI, Bandung.

(2002), Melacak Seni

Pertunjukan Indonesia di Era Globalisasi, Gadjah Mada University Press., Yogyakarta.

SY, Hasnah. (2013), Seni Tari dan Tradisi yang Berubah; Studi Terhadap Penciptaan Kolektif dan Perubahan Tari Tangan Oleh Masyarakat Padang Laweh, Media Kreativa, Jogjakarta.

Syahrani, Aliman. (2012), Menjembara Jejak Berlari: Dindang Ligum Karasmin Hulu Sungai Selatan, Pemerintah Kabupaten Hulu Sungai Selatan Dinas Kebudayaan dan Pariwisata, Hulu Sungai Selatan.

Rusmiadi, Iskandar, Ady Prayitno, Nanang Syaifuddin, \& Amrullah. (2010), Tari Kanjar, Musium Lambung Mangkurat, Banjarbaru. 
Rahmani dan I Wayan Dana (FUNGSI TARI BABANGSAI DALAM UPACARA ARUH GANAL DI DESA LOKSADO HULU SUNGAI SELATAN KALIMANTAN SELATAN)

JOGED

ISSN: 1858-3989 